Research Journal of Applied Sciences 14 (6): 208-214, 2019

ISSN: 1815-932X

(C) Medwell Journals, 2019

\title{
Evaluation of Local Road Handling Program (The Role of Human Resources)
}

\author{
Hasina, Hamidah and Dedi Purwana \\ Universitas Negeri Jakarta, Jakarta, Indonesia
}

\begin{abstract}
This research performed to determine the five aspects that includes the context which contained policies goals and objectives of the program, input aspect, process aspect, product aspect and outcome aspect of accelerated development and preservation of material based local roads in Northern Buton District during the year 2010-2014 in terms of role of human resources in realizing program objectives. The approach used in this study is a qualitative approach by selecting CIPPO evaluation model developed by Stufflebeam. Data and information are captured qualitatively and analyzed quantitatively with the main instrument are questionnaires and confirmed by interviewed with key informants and adequate observation. The result of the study concluded that context aspect has an index with good category, the input aspect has an index with fairly good, the process aspect has an index with fairly good, the product aspect has an index with the good category and the outcome aspect has an index with good category. The most influential component in this study are the role of human resources in the form of innovation, competency, creativity and the role of leader of public works and spatial planning services department of Northern Buton District in creating changes both in the teams and individuals in the organizations. The study also found that organization culture applied principles and philosophy permission to failure, community engagement and empowerment using an local wisdom and social capital approach in this program and introduction to usage of substandard material as substitution of common standard material which is usually used for forming local pavement layers.
\end{abstract}

Key words: Context input, process, product and outcome evaluation, the role of human resources, community engagement and empowerment, local wisdom and social capital, substandard material, permission to failure

\section{INTRODUCTION}

The difficulty of transportation makes it difficult for most people to obtain production facilities, as well as channeling community agricultural products. The two-lane highways constitution of a significant component of the service and essential functions for the movement of people and goods (Al-Kaisy et al., 2018). It is hoped that in the future a variety of innovative value pricing schemes have been applied in the US to mitigate traffic congestion in a sustainable manner. Fan and Jiang (2018) as was done in the United States. Fast and Intertwined Regular (FAIR) highway has been proposed as a road pricing concept that attributes credit to the low-income commuters. Fan et al. (2016) human resource development (PSDM) is basically a form of business in order to increase resilience and competitiveness against the threat of the external environment which is also seen as an effort to increase innovative power in order to create opportunities. Challenges in regional conditions, limited funding and the high cost of road construction using standard materials, prompted the government to obtain the best formulation to accelerate road construction. By scrutinizing the implementation of a long-range road network plan, the study puts emphasis on the consistency of previously compartmentalized development steps. One of the fundamental obstacles faced in the development process in developing countries such as Indonesia is the unavailability of sufficient funds. Hasiani (2015) problems are not only related to limited funds but also related to the construction costs of conventional road construction using concrete asphalt. One of the infrastructures that plays a major role in accelerating development is transportation infrastructure. Transportation infrastructure consists of land transportation, river/sea transportation and air transportation. The development of transportation infrastructure is carried out in accordance with the needs, so that, infrastructure can carry out its functions properly. The government controls the degree of reliability of the entire transportation system, unstable infrastructure, whose capacity decreases when a disaster occurs and stable infrastructure, whose capacity is constant regardless of the occurrence of disaster (Itoh, 2018) the role of the government is very necessary. The limited means of transportation at the beginning of the establishment of an area also resulted in the community experiencing difficulties in developing their economic activities. The limitations faced by the newly formed government, it will be very visible that the role of Human Resources (HR) is very crucial to optimize the utilization of other resources to support the acceleration of the development of local roads. The government focuses on road construction in the first 5 year period which is motivated by a logical

Corresponding Author: Hasina, Universitas Negeri Jakarta, Jakarta, Indonesia 
consideration that most villages and sub-districts do not yet have adequate transportation facilities. The office of public works and spatial planning is the spearhead to realize all plans for accelerating the opening of access by building local roads and supporting facilities (bridges, drainage and duikers), then the role is optimized by adding spatial functions. Ideas in utilizing local materials arise because of the high price of oil asphalt while natural asphalt is available. Innovations and breakthroughs carried out by the leaders of the PUPR office in implementing the acceleration of road handling are of course supported by adequate human resources involvement/participation and empowerment of communities and other stakeholders and supported by the abundant availability of existing materials. HR development in the public works department is for long-term interests and is an important part of the organization itself. The purpose of an empowerment is to develop the community to be independent and prosperous, that the goal of an empowerment is expected to be able to generate all abilities possessed by the community, so that, they can achieve the goals of motivation, initiative, creativity and appreciation and fear for those who excel. This research focuses on the evaluation of the P3JL-BMS (local road handling) program carried out by the PUPR office. Evaluation is carried out towards the achievement of program goals and objectives, resources used in the form of both human resources and local materials used.

Research program: In particular, the purpose of this study are to:

- Describing and analyzing context aspect in handling road program in local road handling program at Northern Buton Regency?

- Describe and analyzing input aspect in handling road program in local road handling program at Northern Buton Regency?

- Describe and analyzing process aspect in handling road program in local road handling program at Northern Buton Regency?

- Describe and analyzing product aspect in handling road program in local road handling program at Northern Buton Regency?
- Describe and analyzing outcome aspect in handling road program in local road handling program at Northern Buton Regency?

\section{Literature review}

The concept of program evaluation: The flow of research that refers to a number of theories in strengthening the evaluation of the local road handling program in Northen Buton Regency of Southeast Sulawesi Province is the focus of the research. From the program evaluation, recommendations are expected to emerge to improve the performance of the public works and spatial planning department in Northern Buton Regency (Fig. 1).

Evaluation can be interpreted as a process of measuring the effectiveness of strategies used in an effort to achieve goals. Data obtained from these measurements is generally, used as an analysis of the next program situation.

The concept of evaluation proposed by Royse, Thyer and Padgett states. Evaluation is the process of systematic collecting and analyzing information in order to form value judgment based on firm evidence. These judgment are concerned with the extent to which particular target are being achieved. Translated into evaluation is a systematic process in collecting and analyzing data and information for input and consideration of appropriate decision making from data and actual facts (Royse et al., 2010).

Evaluation of road infrastructure is a process of assessing the condition of road infrastructure and informing the success of the road infrastructure development program that has been implemented and the extent to which the program is carried out. The simple steps of MCE proposed by Sanders and Ruiter include: establishing criteria and making classifications, measuring criteria that have been grouped by giving a score/value and standardizing scores which exists. Based on the foregoing, it can be stated that evaluation research (evaluation research) or program evaluation is a scientific method (rational, empirical and systematic) in obtaining data to determine the effectiveness and efficiency of projects, policies and programs. The basic concept of program evaluation is carried out based on the objectives of a program.

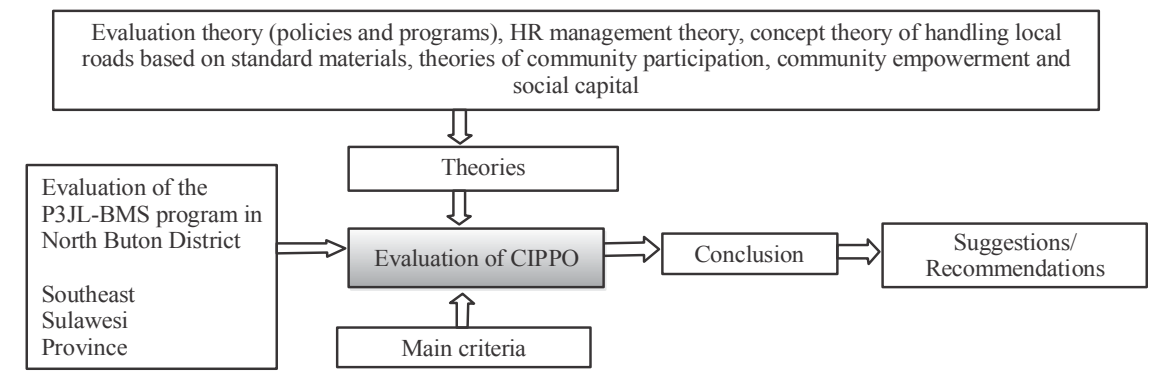

Fig 1: Research flow 
Res. J. Applied Sci., 14 (6): 208-214, 2019

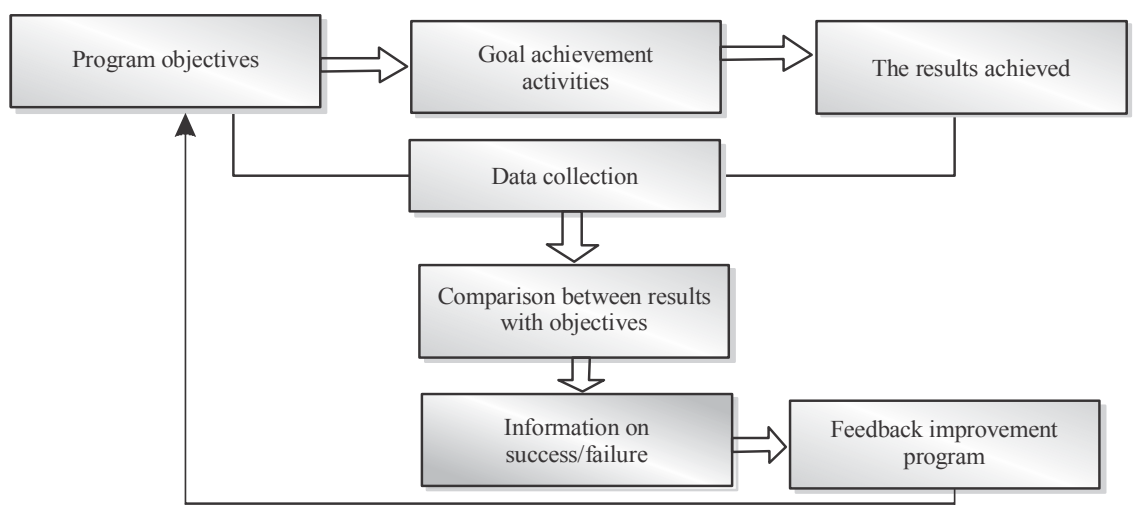

Fig. 2: Basic concept of research program evaluation/evaluation

The basic concept in program evaluation is shown in Fig. 2, it can be seen that evaluation or program evaluation research is carried out based on the objectives of a program.

There are two types of evaluations, namely, formative evaluation and summative evaluation. To understand how the evaluation models work, the following will be explained: goal oriented evaluation model, goal free evaluation model, formative summative evaluation model, countenance evaluation model, CSE-UCLA Model evaluation, CIPP evaluation model, discrepancy model, policy evaluation. After knowing the purpose of the program, the evaluator must also know what activities should or based on the reality of what must be done to achieve that goal.

Activities in evaluation research are comparing the planned activities with the activities carried out and comparing the objectives of the program with the results achieved. Based on the research information will be obtained on how far a plan can be done and how far the goal will be realized. So, in this case it will be known the success or failure of a program. The information obtained is feedback that can be used for program development.

There are several types of evaluation research, depending on the object being evaluated and the purpose of the evaluation. Then stated as follows: perhaps the most important basic distinction is evaluation of types between formative and summative evaluations. The formative evaluation of the delivery or the technology, the quality of its implementation and the program or technology, the quality of its implementation and the assessment of the organizational context, personnel, procedures, inputs and so on.

A complete explanation of the goal oriented evaluation model is the objective-based evaluation model is each type of evaluation based on knowledge and referenced to the objectives of the program, person or product.

The goal free evaluation model is a model that is an evaluation of the actual influence of the objectives to be achieved by the program. Scriven views that program evaluation carried out by evaluators does not need to pay attention to the objectives of the programs that have been set formative summative evaluation model is a model that refers to the stages and scope of the object being evaluated. Formative evaluation is an evaluation carried out when the program is still running or when the program is still close to the beginning of the activity. Countenance evaluation model is a model that emphasizes the implementation of two main things, namely description and consideration and distinguish between the three stages in program evaluation, namely: antecedents or contexts, transactions or processes and outputs or outcomes

CSE-UCLA evaluation model, CSE stands for center for the study of evaluation while UCLA stands for University of Caslifomia in Los Angeles. Evaluation is a convincing process of decision, choosing the right information, collecting and analyzing information, so that, it can report a summary of data that is useful for decision makers in choosing several alternatives.

CIPP evaluation model is an evaluation model developed by stufflebeam which consists of four evaluation components, namely context (context) input (input), process (process) and product (result). The discrepancy model is a model that emphasizes the view of gaps in program implementation. Program evaluation is carried out to measure the amount of gap that exists in each component between what should be achieved and what has already been achieved policy evaluation is evaluation is a process that leads to assessment and decision making regarding a program or activity.

A public policy cannot be left alone. Policies should be monitored and one of these oversight mechanisms is called policy evaluation. Evaluation is usually intended to assess the extent to which the effectiveness of public policies is accountable to the public. The extent to which the goal is achieved. Evaluation is also needed to see the gap between expectations and reality. Most policy experts agree that the final stage of the policy process is the evaluation phase. Lester and Stewart stated that policy evaluation is essentially, the study of the consequences of public policy. Anderson, argues that policy evaluation focuses on estimating, evaluating 
and estimating implementation (processes) and the consequences (impacts) of policies. As a functional activity, policy evaluation can actually be carried out as a whole policy stages not only in the final stages.

Program evaluation: Evaluation can be interpreted as a process of measuring the effectiveness of strategies used in an effort to achieve goals. Data obtained from these measurements is generally used as an analysis of the next program situation. Basically evaluation is a systematic activity carried out to determine the effectiveness of a program, action or policy. Evaluation is also a systematic process for collecting, analyzing and interpreting data (information) to determine the extent to which an organization has reached its stated objectives. Overall it can be assumed that the program includes a plan involving various units that contain policies and a series of activities that must be carried out within a certain period of time.

Objectives of program evaluation: The purpose of the program evaluation is to find out the achievement of program objectives by knowing the implementation of program activities because program evaluators want to know which parts of the program components and sub-components have not been implemented and why.

Program evaluation model: Program evaluation can include policies, programs, projects, functions, bodies or activities that have a purpose or set of goals. Program evaluation can be oriented in the form of a set of activities in an organization or a set of activities in a number of organizations.

\section{Concept of human resources}

Management concept: It means regulating or controlling, concept of Human Resource management HR management in the era of globalization is currently facing various challenges. To be successful, the organization and its leaders must be able to deal effectively with the implications of new technology, globalization, the ever-changing socio-political climate, new competitive challenges, changing economic conditions, changes in customer preferences and new performance standards and laws. The HR management functions are the same as general management functions, namely:

- Managerial function which consists of planning (plannnig) organizing (organizing), directing, controlling (controlling)

- Operational function, consisting of procurement of workers/labor, provision of compensation, integration, maintenance and concentration of employment relations

\section{MATERIALS AND METHODS}

The concept of local road handling program based on substandard material infrastructure concept: Infrastructure is one of the important factors that determine economic development It suggest that infrastructure has the nature of externalities (Canning and Pedroni, 2004) various infrastructures, namely roads, educational facilities, health facilities and so on have the characteristics of positive externalities because these types of infrastructure are able to increase the productivity of all inputs in the production process. Positive externalities in infrastructure can be seen in the spillover effect in the form of increasing production of companies and the agricultural sector without having to increase input of capital and labor as well as being able to increase the level of technology.

Road network system: Law No. 38 of 2007 defines roads as a land connecting infrastructure in any form, not limited to road forms with land surface but also roads that cross large rivers/lakes/seas, below ground and water (tunnels) and above ground level (overpass), covering all parts of the road including complementary buildings which are calculated for traffic (vehicles, people or animals). Not included in this sense are railroads (railroads, lorry roads and cable roads).

Society participation: Participation (involvement) of the community or community towards development programs carried out by the government is divided into eight levels of community or community participation based on the power given to the community:

Citizen control: The public or public can participate (be involved) in and control the entire decision-making process to be taken, delegated power. At this level the community or the public has the authority to make decisions on certain plans.

Partnership: The public or the public has the right to negotiate with the decision maker or the government on a joint agreement of power divided between the community and the government.

Placation: Holders of power (government) need to appoint a number of people from the affected community to become members of a public body.

Consultation: The public or the public are not only notified but also invited to express their input and opinions informing. Holders of power (government) only provide information to the public regarding proposals for activities to be carried out, therapy. The holder of power (government) gives a reason for the proposal by pretending to involve the community. 


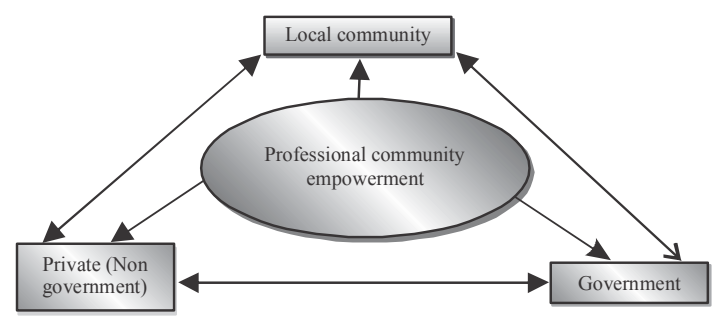

Fig. 3: Collaborative community empowerment scheme

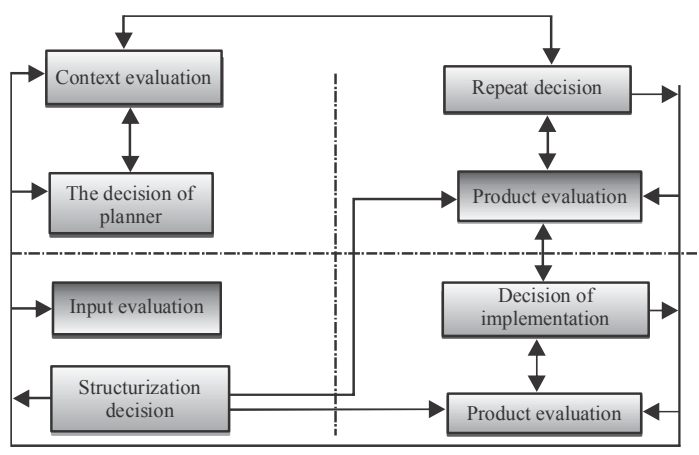

Fig. 4: CIPP evaluation model source: Isaac and Michael

Manipulation: This stage is the lowest level of participation where the public or only the name is used.

Community empowerment: Empowerment or translated into English "empowerment" is a concept that is present as part of the development of the community's mind. Conceptually empowerment comes from the word power (power or empowerment). Schematically, the pattern of relations between the main parties in professional community empowerment can be seen in the following (Fig. 3).

Social capital: Capital is essentially one of the basic elements of wealth and as a means of production that can produce other goods and useful benefits. Components of community capital and the interrelationships with each other can be seen in the following Fig.4 and 5.

CIPPO evaluation model: The evaluation model chosen is CIPP evaluation (contex input, process and product). In its implementation it is more widely used by evaluators, this is because this evaluation model is more comprehensive when compared to other evaluation models.

Research approach: The evaluation research method uses is the evaluation of the CIPPO program. This

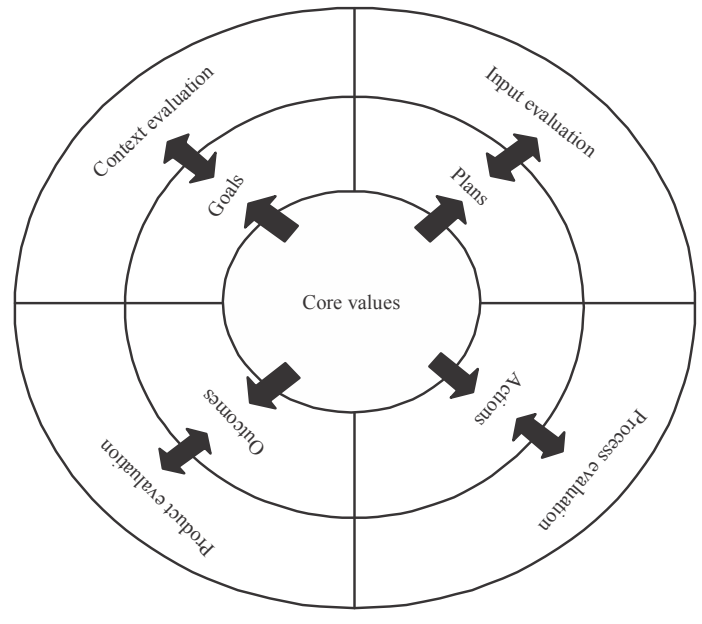

Fig. 5: Key components in the CIPP evaluation model and its relationship to the program, (2014) (Stuleflebeam and Coryn, 2014)

study use mixed method. Data collection techniques in the study will use the following technique: observations, questionnaires and in depth interviews were carried out on key informants who were considered to have adequate knowledge about a problem or phenomenon of the implementation of local road handling program in Northern Buton Regency.

\section{RESULTS AND DISCUSSION}

Evaluation criteria: The evaluation criteria are important to be reference/measure of the success of a program that is evaluated. The success or failure of a program or the effectivenets of a program will be known after the evaluation has been carried out and compared to the criteria that have been determined (Table 1).

Intereviews and questionnaires based on evaluation criteria, then the data obtained from the questionnaires and interviews were processd and next conclusion expressed in terms of rank with according to Likert scale within 5 scales.. The descriptor and rating used in this studi are presented in the following Table 2.

The research find the theoretical model which describe competency innovation, creativity and the role of leader in organizing human resources in Public Works and Spatial Planning department in Northern Buton Regency which supported by individual and teams performance and giving the impact to organizational performance (Fig. 6). 


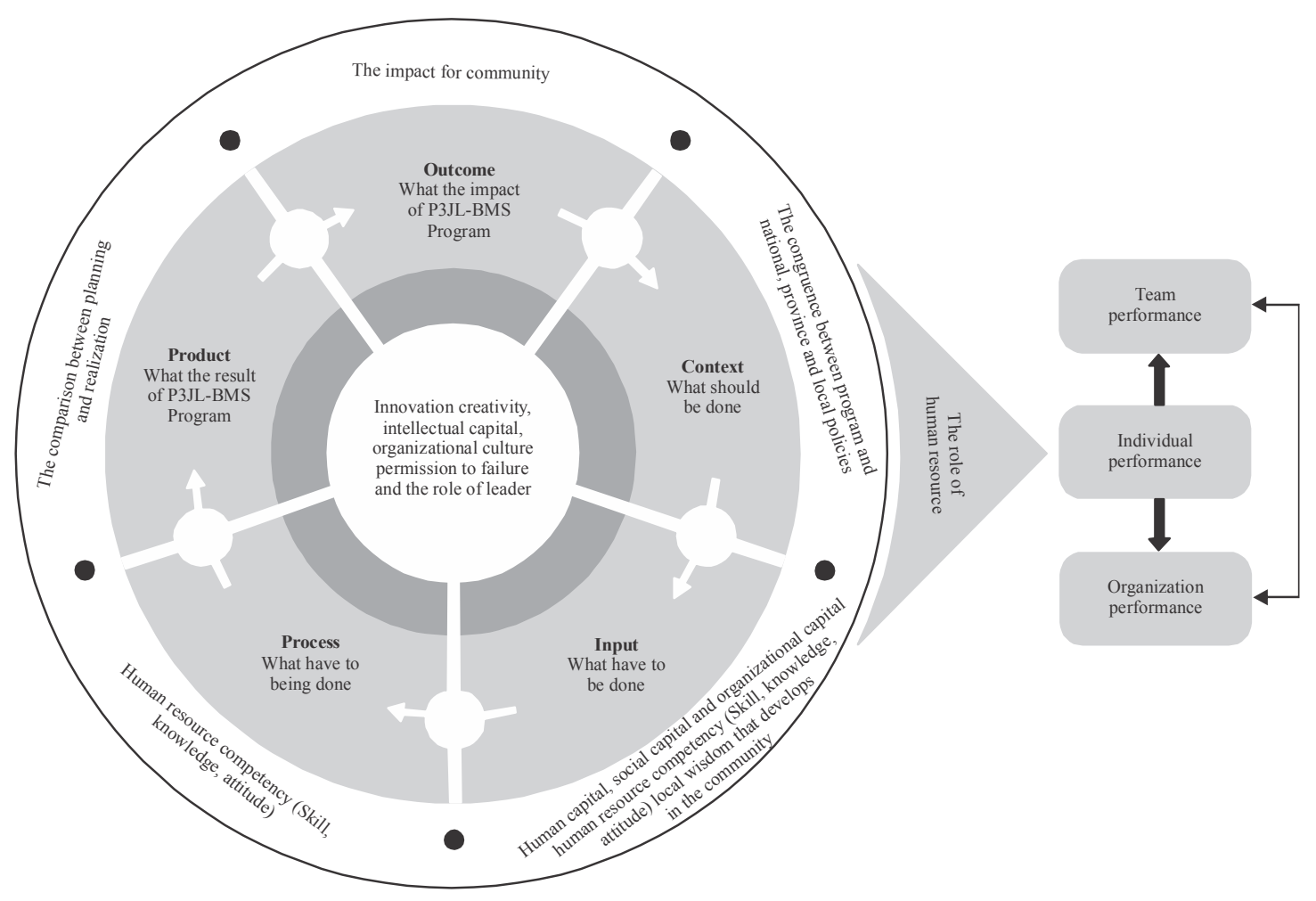

Fig. 6: The theoretical model of research

Table 1: Evaluation criteria for the local road handling program

Evaluation components/Aspect evaluated Evaluation criteria

Program background

The policy

Objectives

The suitability of policies between the central government and local government establishment of local roads based on local materials that are

The difficulty

Acceptance of program

Participation

fast, easy and inexpensive

Feedback

Human resources understand the difficult of this program

Human resources knows the aim of the program

Human resources involved in this program

Human resources input for the planning of program

The ability to do routine task

Human resources gives a good input as feedback of the program

The ability to do concurrent task

The ability of human resources to do routine task, especially, related with choosing a local material, preparing an equipment and the good understanding about the spescification of road

The ability of human resources to do concurrent task, especially, related with understanding choosing a local material, preparing an equipment and the good about the spescification of road

The ability to take quick decision

The ability to work as team

The ability to work adapt in new environment The understanding about the benefit involvement community

Human resources for the program implementation The ability to do routine task

The ability of human resources to make quick decision especially, related with choosing a local material, preparing an equipment and the good understanding about the spescification of road

The ability of human resources to work as team, especially related with choosing a local material, preparing an equipment and the good understanding about the spescification of road

The ability of human resources to adapt in new environment The understanding from human resources about benefit of community involvement in this prorgam

The ability of human resources to do routine task, especially, related with selection of partner of implementing program

The ability of human resources to do concurrent task, especially, related with selection of partner of implementing program

The ability of human resources to make quick decision, especially, related

The ability to take quick decision with selection of partner of implementing program 
Res. J. Applied Sci., 14 (6): 208-214, 2019

Table 1: Continue

\begin{tabular}{|c|c|c|}
\hline Evaluation components/Aspect evaluated & Evaluation criteria & Models \\
\hline The ability to work as team & $\begin{array}{l}\text { The ability of human resources to work as team, especially, related with } \\
\text { selection of partner of implementing program }\end{array}$ & \\
\hline The ability to work adapt in new environment & The ability of human resources to adapt in new environment & \\
\hline $\begin{array}{l}\text { The understanding about the benefit involvement } \\
\text { community }\end{array}$ & $\begin{array}{l}\text { The understanding from human resources about benefit of community } \\
\text { involvement in this prorgam }\end{array}$ & \\
\hline $\begin{array}{l}\text { The understanding about community contribution } \\
\text { for the program }\end{array}$ & $\begin{array}{l}\text { The understanding about the financial contribution of community for } \\
\text { this program }\end{array}$ & \\
\hline \multicolumn{3}{|l|}{ Program result } \\
\hline The result of this program & $\begin{array}{l}\text { Human resources know the benefit program for the region and community } \\
\text { and the result is same with the expectation and prediction }\end{array}$ & Product \\
\hline \multicolumn{3}{|c|}{ 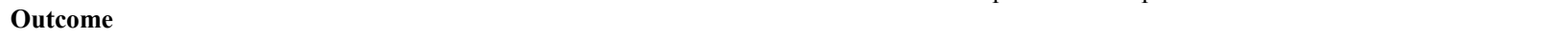 } \\
\hline The impact of the program & $\begin{array}{l}\text { Local materials are used for the program } \\
\text { The problem related access from the village to another village solved } \\
\text { Changing travel patterns and reduce the transportation fee } \\
\text { Increeasing income for people } \\
\text { Increasing the productivity for the people }\end{array}$ & Outcome \\
\hline
\end{tabular}

Table 2: Gaudiness for assessment of evaluation

\begin{tabular}{ll}
\hline Scale of weighting & Categories \\
\hline $1.00-1.79$ & Very bad \\
$1.80-2.59$ & Bad \\
$2.60-3.39$ & Pretty good \\
$3.40-4.19$ & Good \\
$4.20-5.00$ & Very good \\
\hline
\end{tabular}

\section{CONCLUSION}

It can be concluded as follows: content aspects (context) input aspects (input), process aspects (process) aspects of results (output), impact aspects (outcome) had been applied in P3JL-BMS in Northern Buton Regency and determined by the role of human resources in inspiring and encouraging the changes both organizational and individual in achieving purpose and target of local road handling program, The strategy of community engagement, social capital and local wisdom in local road handling program and the usage of substandard material as substitution standard material in local road handling program.

\section{REFERENCES}

Al-Kaisy, A., A. Jafari, S. Washburn, T. Lutinnen and R. Dowling, 2018. Performance measures on two-lane highways: Survey of practice. Res. Transp. Econ., 71: 61-67.
Canning, D. and P. Pedroni, 2004. The effect of infrastructure on long run economic growth. Econ. Dev., 99: 1-30.

Fan, W. and X. Jiang, 2018. Conceptual development and economic evaluation of multilevel premium highways. Res. Transp. Econ., 70: 148-160.

Fan, W., X. Jiang, S. Erdogan and Y. Sun, 2016. Modeling and evaluating FAIR highway performance and policy options. Transp. Policy, 48: $156-168$.

Hasiani, S.F., 2015. Analysis of the human resources and the impact on economic growth in Pelalawan Regency. Jom FEKON, 2: 1-15.

Itoh, R., 2018. Is transportation infrastructure cost recoverable under the risk of disasters? Transp. Res. Part A. Policy Pract., 118: 457-465.

Royse, D.D., B.A. Thyer and D. Padget, 2010. Program Evaluation: An Introduction. 5th Edn., Wadsworth Cengage Learning, Belmont, California, USA., ISBN:9780495601661, Pages: 401.

Ruiter, W. and F.M. Sanders, 1998. Physical Planning: Policies, Methods and Techniques. Delft University of Technology (TU Delft), Delft, Netherlands, ISBN:9789080274358, Pages: 308

Stuleflebeam, D.L. and C.L.S. Coryn, 2014. Evaluation Theory, Models and Applications. 2nd Edn., Jossey-Bass, San Francisco, California, USA., ISBN-13:978-1118074053, Pages: 800. 